\title{
Effects Research of Environmental Hormone BPA and PAEs on the Expression of HSP70-9 Gene in Spinacia oleracea
}

\section{Wenxue Jia, and Peiyong Liu*}

Life Science and Health College, Northeastern University, Shenyang 110004, Liaoning Province, China

\begin{abstract}
Objective: In order to explore the impacts of environmental hormones (EHs) on plants, the relationship between EHs pollutants and Spinacia oleracea HSP70-9 expression was studied in this paper. The researchers studying HSP70 have primarily investigated high temperature stress, low temperature stress, water stress and other environmental factors, such as heavy metals, wind stress, salt stress. However, as a type of environmental pollutant, EHs may affect the growth and development of plants.

Methods: Two typical EHs, PAEs (phthalates esters) and BPA (bisphenol A), were selected for the study. RT-qPCR was used to study HSP70-9 expression at the transcriptional level under single and combined pollution conditions in spinach seedlings.
\end{abstract}

Results: The result of the present study showed that, the spinach HSP70-9 expression is downregulated with single and combined treatments of EHs.

Conclusion: The conclusion is that BPA and PAEs had certain effects on the expression of HSP70-9 in spinach.

\section{Keywords: HSP70; Spinacia oleracea; Gene expression; BPA; PAEs}

\section{Introduction}

Environmental hormones (EHs) are compounds present in the environment which can interfere with normal metabolic activities in organisms [1-5]. EHs are divided into two major heads namely, degradation-resistant organic halogens, which includes pesticides, industrial compounds, heavy metals, organic solvents, estrogens, and second category includes plant growth regulating agents [6,7]. EHs can cause disorders in organisms (animals), such as cancer, genetic mutations, obesity, infertility, Alzheimer's disease and Schizophrenia $[2,4-8]$. However, little is known regarding the harm EHs pose toward plants.

Current researchers who study EHs impact on organisms continue to increase, and have mainly focused on the influence of heavy metals on aquatic animals and plants [9-12], pesticides on insects [11], and EHs on organism genotoxicity [5]. The plasticizers, BPA for clear plastics and PAEs in hard plastics, have some estrogenic activity and anti-androgenic activity [4]. With the improvement of living standards, plasticizers such as BPA and PAEs are appearing more frequently in our daily lives, and their impacts to organisms are becoming increasingly prominent [4]. $\mathrm{BPA}$ and PAEs mimic the functions of estrogens and anti-androgens [4]. Nonyl phenol (NP), BPA, EE (17 $\alpha$ - ethinyl estradiol) and DEHP (one type of PAEs) treatments caused a significant increase of HSP70 in chironomids (Chironomus tentans) [11]. With the exception to heavy metals researchers, there are few current researchers studying EHs in plants, and whether BPA and PAEs impact spinach remains unknown.

Plants experiencing adversity can produce some novelty proteins or shut down some proteins biosynthesis to resist the impact of a single stress or combined stress [13-15]. Although heat shock proteins (HSPs) were discovered and named after their response to thermal stress [16], HSPs are not only regulated by temperature stress, but induced by a range of other environmental stress, such as salinity, cold and heavy metals [17]. Generally it is agreed with that HSPs (especially the HSP70 and HSP90 families) play an important role in alleviating the damage caused by various environmental stresses $[13,18]$. HSPs can be divided into five major families: HSP100, HSP90, HSP70, HSP60 and small HSP family $[19,20]$. Among these families, HSP70 family is the highly conserved and the most researched gene family $[11,15,17,20$ 24]. Studies have demonstrated that heat stress [15,18-20,24-32], Cold stress $[15,24,26,29,30]$, water stress $[22,25,26,33,34]$, oxidative stresses $[19,20,22]$, heavy metals $[9,12,13,35]$, salt stress $[13,19,20,22,34]$, light stress [27], and chemical contaminants [11,15,18,19,25,35-37], among others factors, can induce HSP70 [11,14,22,24,35-41]. In plants, HSP70 are categorized into four major subgroups based on the unique and highly conserved C-terminus motif, including the cytosolic, endoplasmic reticulum (ER), mitochondrion (MT) and chloroplast (CP) group [25,42]. However, studies support that HSP70 located specific subcellular has different responses to different environmental stresses [14]. The product of HSP70-9 located in chloroplasts in spinach [31]. Chloroplasts are the important organelles in plants and conduct the organic energy transformation from solar energy. Otherwise, many studies have shown that the activity and quantity of plant chloroplasts decreased under many stresses. So we want to study whether the HSP709 mRNA expression changes under the conditions of BPA and PAEs pollution.

Spinacia oleracea has broad leaves and rapid growth and is rich in metal elements and nutritional characteristics; therefore, this plant is an important vegetable in daily life $[9,43]$. We have selected BPA and PAEs to study in both single and combined contaminant conditions on spinach, measuring the HSP70-9 expression. The result may provide a reference

*Corresponding author: Peiyong Liu, Life Science and Health College Northeastern University, Shenyang 110004, Liaoning Province, China, Tel: +86138-9880-3939; E-mail: liupy@mail.neu.edu.cn

Received February 11, 2017; Accepted February 22, 2017; Published February 27, 2017

Citation: Jia W, Liu P (2017) Effects Research of Environmental Hormone BPA and PAEs on the Expression of HSP70-9 Gene in Spinacia oleracea. J Environ Anal Toxicol 7: 438. doi: 10.4172/2161-0525.1000438

Copyright: ( $2017 \mathrm{Jia}$ W, et al. This is an open-access article distributed under the terms of the Creative Commons Attribution License, which permits unrestricted use, distribution, and reproduction in any medium, provided the original author and source are credited. 
value for environment pollution control and ecological restoration and may be especially pertinent to the impact of environmental pollutants on crops.

\section{Materials and Methods}

\section{Preparation of EHs solutions of BPA and PAEs}

The PAEs solution was prepared from DBP (dibutyl phthalate) and DEHP (diethylhexyl phthalate) by volume ratio of 9:1. Gradient dilution of the PAEs solution was used to obtain five concentrations $\left(\mathrm{mg} \cdot \mathrm{L}^{-1}\right): 0$, 0.5, 5, 10, 50 (as specified in "Research of Chinese Environment PAEs Compounds Contamination and Soil Environmental Quality Standard"). The BPA solution was prepared using gradient dilution to obtain five concentrations (mg.L $\left.\mathrm{L}^{-1}\right): 0,0.05,0.5,5,50$ (as specified in "Summarize of Environmental Behavior for Typical Environmental Hormones BPA"). We carried out a pairwise comparison of the combined BPA and PAEs solution with the BPA and PAEs single solutions. There were 25 groupsolutions of BPA and PAEs single solutions and combined solutions, as shown in Table 1 . All of the solutions were sterilized for $20 \mathrm{~min}$ at $120^{\circ} \mathrm{C}$ and used for treatment after cooling.

\section{Plant materials}

Spinach (Spinacia oleracea L.) seeds were purchased from the Shenyang Agricultural University seed company in China. The seeds were disinfected in $0.1 \% \mathrm{KMnO}_{4}$ for $15 \mathrm{~min}$ and rinsed with distilled water. Dried seeds were cultured in an intelligent light incubator and fertilized with 25 different concentrations of $\mathrm{EH}$ solutions. The culture temperature was $15^{\circ} \mathrm{C} \pm 1^{\circ} \mathrm{C}$ and $12 \mathrm{~h}$ light after $12 \mathrm{~h}$ dark. Approximately 4 weeks later, experiments were initiated when the seedlings developed to their true leaf stage.

\section{RNA extraction and RT-PCR}

Total RNA was extracted from different Spinach leaf samples with Trizol Reagent (BioTeke Biotechnologies Inc., Beijing, China). We prepared the RNA according to the method recommended by manufacturers (Tiangen Biotech (Beijing) Co., Ltd., Beijing, China). The cDNA strand was synthesized resulting in a final volume of $20 \mu \mathrm{L}$, including $1 \mu \mathrm{L}$ total RNA, $5 \times 2 \mu \mathrm{L}$ gDNA Buffer, $10 \times 2 \mu \mathrm{L}$ Fast RT Buffer, $1 \mu \mathrm{L}$ RT Enzyme Mix, $2 \mu \mathrm{L}$ FQ-RT Primer Mix, and $12 \mu \mathrm{L}$ DEPCtreated water. The RT-PCR products were used for $\mathrm{qPCR}$ or stored at $-20^{\circ} \mathrm{C}$.

\section{qPCR}

All qPCR primers were designed using Primer Premier 5 and Oligo 7 software (Table 2), and synthesized by Shanghai Sangon Corporation (all primers had their purity qualified by mass spectrometry).

qPCR was used to detect the gene expression of Spinach HSP70-9. 16s rRNA was used as the reference. The PCR mix had a total volume

\begin{tabular}{|c|c|c|c|c|c|}
\hline EHs Solutions/mg- $\mathrm{L}^{-1}$ & \multicolumn{5}{|c|}{$\mathrm{BPA}$} \\
\hline \multirow{3}{*}{ PAEs } & $\mathrm{P}_{0} \mathrm{~B}_{0}$ & $\mathrm{~B}_{0.05}$ & $\mathrm{~B}_{0.5}$ & $\mathrm{~B}_{5}$ & $\mathrm{~B}_{50}$ \\
\cline { 2 - 7 } & $\mathrm{P}_{0.5}$ & $\mathrm{P}_{0.5} \mathrm{~B}_{0.05}$ & $\mathrm{P}_{0.5} \mathrm{~B}_{0.5}$ & $\mathrm{P}_{0.5} \mathrm{~B}_{5}$ & $\mathrm{P}_{0.5} \mathrm{~B}_{50}$ \\
\cline { 2 - 7 } & $\mathrm{P}_{5}$ & $\mathrm{P}_{5} \mathrm{~B}_{0.05}$ & $\mathrm{P}_{5} \mathrm{~B}_{0.5}$ & $\mathrm{P}_{5} \mathrm{~B}_{5}$ & $\mathrm{P}_{5} \mathrm{~B}_{50}$ \\
\cline { 2 - 7 } & $\mathrm{P}_{10}$ & $\mathrm{P}_{10} \mathrm{~B}_{0.05}$ & $\mathrm{P}_{10} \mathrm{~B}_{0.5}$ & $\mathrm{P}_{10} \mathrm{~B}_{5}$ & $\mathrm{P}_{10} \mathrm{~B}_{50}$ \\
\hline & $\mathrm{P}_{50}$ & $\mathrm{P}_{50} \mathrm{~B}_{0.05}$ & $\mathrm{P}_{50} \mathrm{~B}_{0.5}$ & $\mathrm{P}_{50} \mathrm{~B}_{5}$ & $\mathrm{P}_{50} \mathrm{~B}_{50}$ \\
\hline
\end{tabular}

The letters $B$ and $P$ mean BPA and PAEs respectively and subscripts indicate concentrations. Such as, $P_{0.5}$ is as a representative of PAEs single contamination of $0.5 \mathrm{mg} \cdot \mathrm{L}^{-1} ; \mathrm{P}_{0.5} \mathrm{~B}_{0.05}$ is as a representatives of PAEs and BPA combined pollution with concentrations of $0.5 \mathrm{mg} \cdot \mathrm{L}^{-1}$ and $0.05 \mathrm{mg} \cdot \mathrm{L}^{-1}$. The same to that are below.

Table 1: Preparation of different concentrations solution for BPA and PAEs. of $20 \mu \mathrm{L}$, containing $0.5 \mu \mathrm{L} \mathrm{cDNA}, 0.4 \mu \mathrm{L}$ of $10 \mu \mathrm{M}$ forward primer, 0.4 $\mu \mathrm{L}$ of $10 \mu \mathrm{M}$ reverse primer, $10 \mu \mathrm{L}$ of $2 \mathrm{x}$ Power SYBR Real-timePCR Premixture (BioTeke Biotechnologies Inc., Beijing, China), and $8.7 \mu \mathrm{L}$ sterile water. The reaction program was as follows: initial denaturation at $95^{\circ} \mathrm{C}$ for $2 \mathrm{~min}, 45 \mathrm{cycles}$ at $95^{\circ} \mathrm{C}$ for $20 \mathrm{sec}, 56^{\circ} \mathrm{C}$ for $20 \mathrm{sec}, 72^{\circ} \mathrm{C}$ for $20 \mathrm{sec}$. The melting curve procedure was as follows: denaturation at $95^{\circ} \mathrm{C}$ for $15 \mathrm{sec}$, and an increase of $65^{\circ} \mathrm{C}$ up to $95^{\circ} \mathrm{C}$ at a rate of $0.5^{\circ} \mathrm{C} / \mathrm{s}$. PCR amplification was performed in the ABI StepOne ${ }^{\mathrm{mm}}$ Real-Time PCR System (ThermoFisher, USA).

The $2^{-\triangle \Delta C T}$ method was used to calculate the resulting data [44]. The experimental results were performed by SPSS 18.0 (SPSS Inc., USA) software for One-Way ANOVA and the LSD (Least Significant Difference) test was used to compare the differences among means of treatments. Differences were considered statistically significant at $\mathrm{P}<0.05$ and very significant at $\mathrm{P}<0.01$.

\section{Results}

\section{Spinach HSP70-9 expression influenced by single pollutants of BPA and PAEs}

To test whether spinach HSP70-9 gene expression was regulated by BPA and/or PAEs, total RNA was isolated from spinach seedling, which had been treated (except the control) with BPA and/or PAEs and subjected to RT-qPCR. Figure 1 shows the relative levels of Spinacia oleracea HSP70-9 expression when influenced by BPA (A) and PAE (B) single pollution. These results indicate that HSP70-9 exhibits similar expression patterns under the single BPA and PAEs contaminant treatments, and HSP70-9 is significantly downregulated when exposed to both. Moreover, when the same HSP70-9 exposed to the single BPA pollution treatment (Figure 1A) and single PAEs pollution treatment (Figure 1B), with the exception of the $\mathrm{B}_{5}$ treatment group, HSP70-9 has been shown to significantly downregulated in the treatment groups compared with the control groups. In addition, with the exception of $\mathrm{B}_{50}$ treatment group, the expression level of HSP70-9 increased with the increase of EHs concentration in each treatment group. Finally, HSP709 has minimal expression under the $\mathrm{B}_{50}$ and $\mathrm{P}_{0.5}$ concentrations.

\section{Spinach HSP70-9 expression influenced by combined pollutants of BPA and PAEs}

In general, environmental pollutants usually coexist together with other environmental pollutants. So it is interesting to study the combined effects of BPA and PAEs on spinach seedling. The relative expressions of spinach HSP70-9 appear to be influenced by the treatment of combined BPA and PAE contaminant (Figure 2A-2D). All groups showed the same downregulated expression patterns. In addition, the expression level of HSP70-9 increased with the increase of EHs concentration in each treatment group. Finally, HSP70-9 has minimal expression under the $\mathrm{P}_{0.5} \mathrm{~B}_{0.05}, \mathrm{P}_{5} \mathrm{~B}_{0.05}, \mathrm{P}_{10} \mathrm{~B}_{0.05}$ and $\mathrm{P}_{50} \mathrm{~B}_{0.5}$ combined pollutions.

\section{Discussion}

As a category of environmental pollutants, EHs are bound to affect

\begin{tabular}{|c|c|c|c|c|}
\hline Gene & Sequence (5'-3') & $\begin{array}{l}\text { Length, } \\
\text { bp }\end{array}$ & $\begin{array}{l}\text { Product, } \\
\text { bp }\end{array}$ & GenBank ID \\
\hline \multirow{2}{*}{$\begin{array}{l}\text { HSP70- } \\
9\end{array}$} & F: CTTCTATTGGATGTTGCACCT & 20 & \multirow{2}{*}{187} & \multirow{2}{*}{ AF035456 } \\
\hline & R: TAAGATCGAATTTCCCGAGA & 21 & & \\
\hline \multirow{2}{*}{$\begin{array}{l}16 S \\
\text { rRNA }\end{array}$} & $\begin{array}{l}\text { F: } \\
\text { CCCAACGTCAGTTTTTTCTATTTTGA }\end{array}$ & 25 & \multirow[t]{2}{*}{72} & \multirow{2}{*}{$\begin{array}{l}\text { J01440(Chen } \\
\text { and Arora, } \\
2014 \text { ) }\end{array}$} \\
\hline & R: CCACGAGCCTCTTATTCATTCTC & 23 & & \\
\hline
\end{tabular}

F: Forward; R: Reverse.

Table 2: Primer sequences for the qPCR amplification of specific genes. 


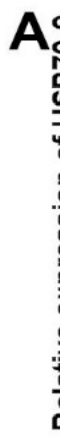

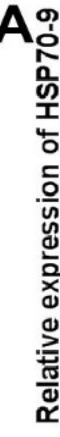

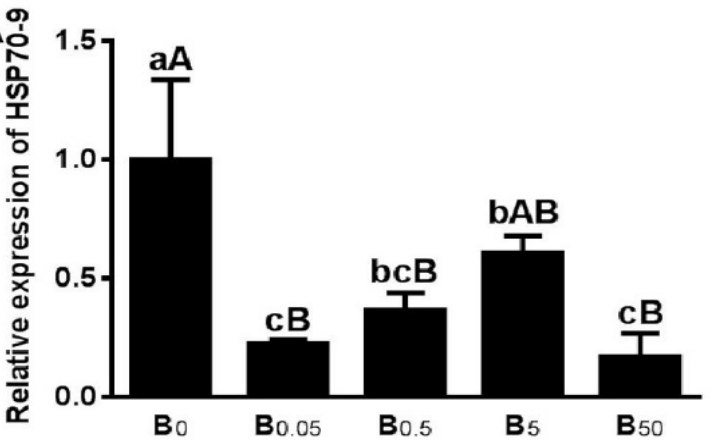

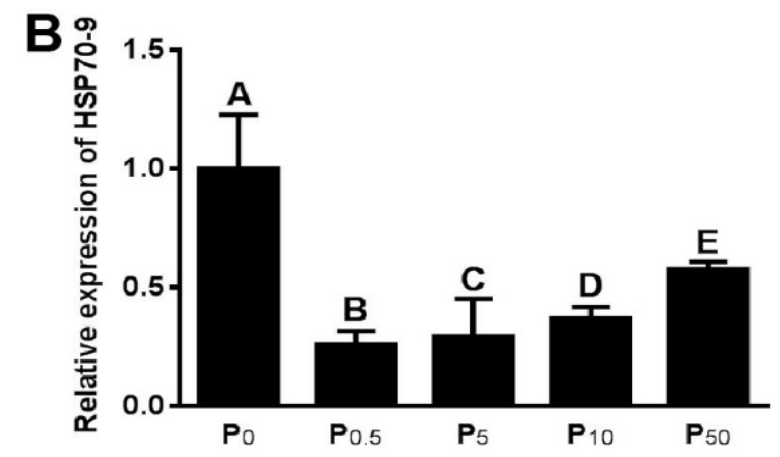

Figure 1: Relative levels of Spinacia oleracea HSP70-9 expression when influenced by BPA (A) and PAE (B) single pollution.
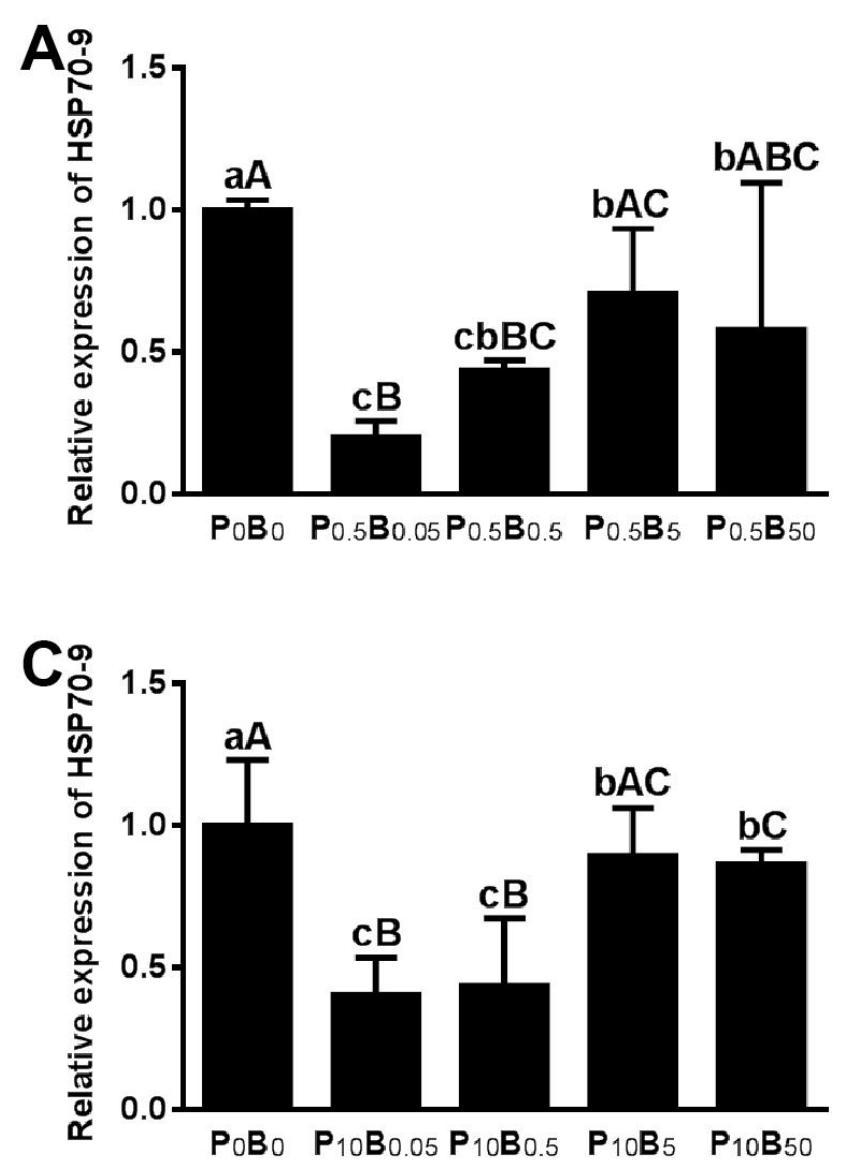
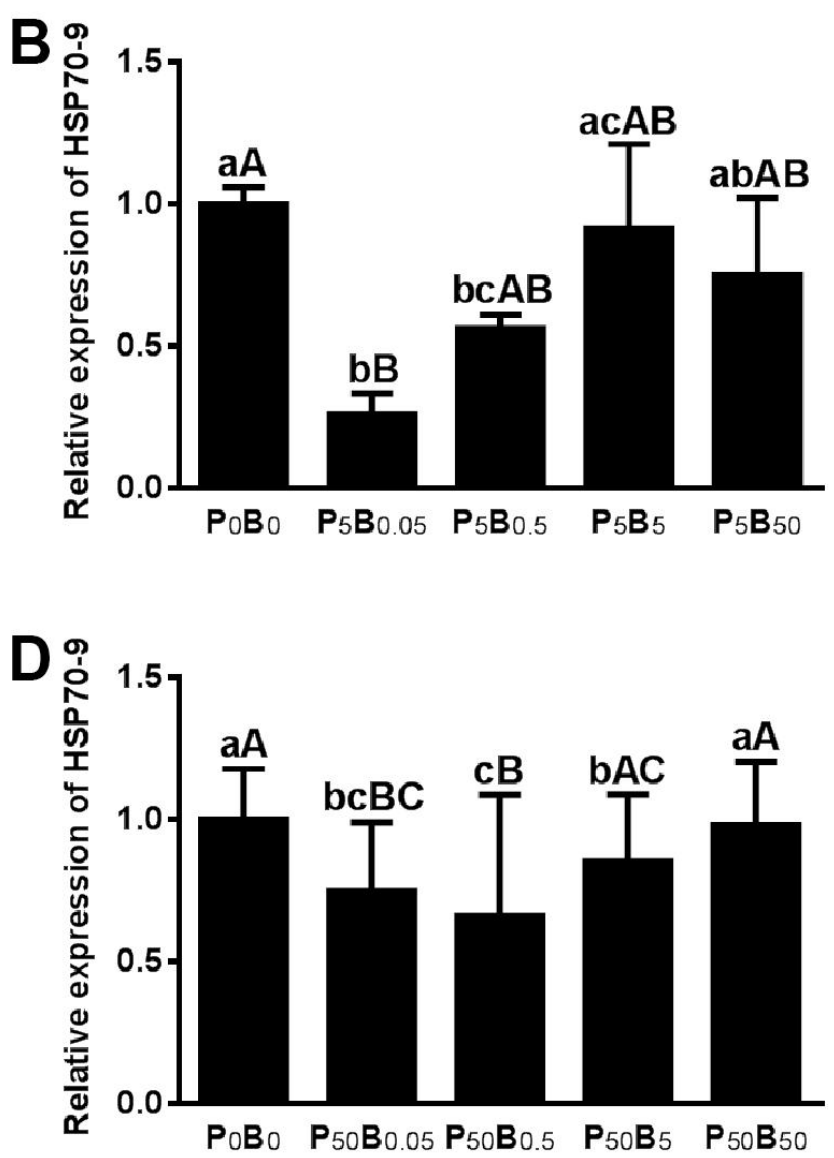

Figure 2: Relative expressions of spinach HSP70-9 appear to be influenced by the treatment of combined BPA and PAE contaminant.

the expression (up or down regulation) of certain genes in organisms living in harmful environments, whether directly or indirectly [11]. It may therefore be reasonable to assume that there are genetic mechanisms that resist or adapt to this type of adverse environment. However, each organism experiences distinct pathways for genetic inheritance and evolution, so EHs-induced expression varies among genes, gene number and the forms of impact.

Traditionally, the impact of environmental stressors on plants is studied mainly by measuring plant height, root length, biomass and various methods for determining physiological and biochemical parameters. However, many recent studies on plant stress have been carried out using molecular biology techniques [29,45,46]. In this paper, a more sensitive molecular biology method, RT-qPCR, was used in the present study to detect spinach HSP70-9 expression at a transcriptional level in response to single and combined treatments of EHs.

Lee et al. suggested that, the response of the HSP70 expression by BPA and DEHP (one of PAEs) exposure was sensitive to low concentrations in Chironomus tentans [11]. Duan et al. found that 
Citation: Jia W, Liu P (2017) Effects Research of Environmental Hormone BPA and PAEs on the Expression of HSP70-9 Gene in Spinacia oleracea. J Environ Anal Toxicol 7: 438. doi: 10.4172/2161-0525.1000438

Page 4 of 6

salicylic acid (SA), ethylene (ET) and abscisic acid (ABA) treatments had no influence on chloroplastic HSP70 expression in wheat [18]. Spinach HSP70 have sensitive response to heat [26-28,32], cold $[28,47]$, water [26], wound [26] and heavy metal stress [9,12]. As showed in Figure 1 and Figure 2, the present study quantitatively analyzed the expression of spinach HSP70-9 at the transcriptional level in response to the EHs, BPA and PAEs in both single and combined pollution treatments. The HSP70-9 expression in all treatment groups were all downregulated compared with the control groups.

Plants treated by EHs or other stress have a decrease of chlorophyll content, biomass $[9,12,22,48,49]$. It is suggested that the plant life activities have been seriously affected in the adverse environment. Researchers suppose that chloroplast has damaged since the chlorophyll content decreased and newly synthesized chloroplastic HSP70 may fail to enter chloroplasts after stress and may be degraded in the cytoplasm [31]. Thus, the downregulated expression of spinach HSP70-9 which located in chloroplast seems to be reasonable.

Although HSP70 members share a conserved structure and a similar mechanism, they have different mechanisms in forming chaperone complexes and performing their function in stress $[30,50]$. The specific roles of individual HSP70 proteins are likely to be determined by their location in different subcellular compartments [17,30], the cytosolic HSP70 prevents protein aggregation, assists de novo protein folding and maintains the organellar precursor proteins in an import-competent stage, and the ER, mitochondrial and chloroplastic HSP70 proteins are involved in precursor protein import and translocation [23,31,51,52]. So we assume that organelles and cytosolic HSP70 of Spinacia oleracea possibly work through different molecular mechanisms in responding to specific stress.

As a chaperone molecule, HSP70 performs various functions, such as folding unfolded proteins, targeting and degrading denatured proteins, monitoring proteins for correct folding, and transporting and positioning the precursors of mature proteins $[17,53]$. Masand et al. found that, proteolytic activity was significantly increased in wild type compared to transgenic plants under different abiotic stresses in Arabidopsis thaliana [22]. The total protein is decreased under the treatment by BPA and PAEs single and combined solutions in Glycine max (data not show). Heavy metal concentrations also had a significant adverse impact on total protein in Spinacia oleracea [9]. As shown in Figure 1, the spinach HSP70-9 expression shows an upward trend as BPA and PAEs concentrations increase. This finding suggests that the increased EHs lead to the denaturation of spinach seedling proteins. Since chaperone proteins may play a vital role in the cell homeostasis, the increased expression of HSP70-9 could indicate chaperone proteins' role in restoring denatured proteins and preventing the degeneration of aggregated proteins [46], among other functions, after exposure to EHs.

Research shows that the impacts caused by combined pollutants were more serious than a single pollution [1]. Furthermore, the coexistence of various EHs is a current environmental issue. Therefore, it is necessary to study the environmental impacts of combined $\mathrm{EH}$ pollutants on plants. Figure 2 shows the spinach HSP70-9 expression on transcriptional level under BPA and PAEs combined contaminants. It shows similar expression patterns to the expression patterns displayed under single $\mathrm{EH}$ pollutions. The study of heavy metals pollutants treatments on spinach, including $\mathrm{Cd}, \mathrm{Pb}$ and $\mathrm{Zn}$, suggest that the impact of combined pollution is stronger than that of single pollutions, but weaker than the mathematical addition of two single pollutions' impact [9]. A study of $\mathrm{Cd}$ and $\mathrm{NaCl}$ pollutants suggest that the expression of spinach HSP70 is significantly increased under the combined pollution, but unchanged under either individual pollution [13]. Comparing Figure 1 and Figure 2, HSP70-9 expression under combined pollutants appears lower than expression in response to single pollutions, with the exception of the $\mathrm{P}_{10}$ BPA. This finding suggests that spinach uses different mechanisms to respond to combined and single EHs pollution [13], but the same response protein in both mechanisms is HSP70. The induction of HSP70 under environmental stress is regulated by heat shock transcription factors (HSF) and corresponding heat shock elements (HSE) in the promoters [24]. Therefore, it is necessary to study the mechanism of HSP70 in response to environmental stress from the molecular level by further study the interaction between HSF, HSE and HSP70.

Spinach response and resistance to these environmental stressors not only depend on specific proteins or signaling pathways, but the combined effects of a variety of proteins and signaling pathways [13]. Meanwhile, with the large variety of EHs and the wide functional range of pollutions, it is presumable that, the long-term effects of EHs on organisms will be a long and difficult task. Therefore, genomics, transcriptomics, proteomics and other similar methods should be used to explore the single and combined pollution response mechanisms of plants.

\section{Conclusions}

In this study, two common EHs, BPA and PAEs, were used to detect the expression of spinach HSP70-9 using RT-qPCR under different concentrations of single and combined pollution conditions. The results show that under BPA and PAEs, single contaminant conditions, spinach HSP70-9 expression shows an overall trend toward downregulation. Under the combined BPA and PAEs treatment conditions, all treated groups also presented downregulated HSP709 expressions; however, spinach HSP70-9 expression was higher in combined pollutant conditions than in single pollution conditions. As a type of responsive protein, spinach HSP70 has an important role in the resistance and adaptation mechanisms responding to adverse environments containing BPA and PAEs.

\section{Acknowledgments}

This work was supported by the Scientific Research Fund of Liaoning Provincial Education Department (Grant No. L20150175).

\section{Author Contributions}

Conceived and designed the experiment: Peiyong Liu. Performed the experiments and analyzed the data: Wenxue Jia. Contributed reagents/materials/analysis tools: Wenxue Jia and Peiyong Liu. All authors were involved in writing the paper and approved the final manuscript.

\section{Conflicts of Interest}

The authors declare no conflicts of interest.

\section{References}

1. Esteban S, Llamas PM, Garcia-Cortes H, Catala M (2016) The endocrine disruptor nonylphenol induces sublethal toxicity in vascular plant development at environmental concentrations: A risk for riparian plants and irrigated crops. Environ Pollut 216: 480-486.

2. Hong H, Shen J, Ng HW, Sakkiah S, Ye H, et al. (2016) A rat alpha-fetoprotein binding activity prediction model to facilitate assessment of the endocrine disruption potential of environmental chemicals. Int J Environ Res Public Health 13: $1-18$. 
Citation: Jia W, Liu P (2017) Effects Research of Environmental Hormone BPA and PAEs on the Expression of HSP70-9 Gene in Spinacia oleracea. J Environ Anal Toxicol 7: 438. doi: 10.4172/2161-0525.1000438

3. Patrick SM, Bornman MS, Joubert AM, Pitts N, Naidoo V et al. (2016) Effects of environmental endocrine disruptors, including insecticides used for malaria vector control on reproductive parameters of male rats. Reprod Toxicol 61: 19-27.

4. Shore LS, Bar-EI CK (2010) The environmental compartments of environmental hormones. Reviews on Environmental Health 25: 345-350.

5. Zhang C, Li YH, Mo LY, Qin LT (2013) Genotoxicity of environmental hormones: a review. Adv Materials Res 864: 172-178.

6. Atsuji S, Ueda K, Fujimoto R (2013) Our stolen sustainability: unsafe eden contaminated by environmental hormones. Information Research: Kansai University Faculty of synthesis intelligence summary pp:1-20.

7. Maqbool F, Mostafalou S, Bahadar H, Abdollahi M (2016) Review of endocrine disorders associated with environmental toxicants and possible involved mechanisms. Life Sci 145: 265-273.

8. Zhang Y, Dong S, Wang H, Tao S, Kiyama R (2016) Biological impact of environmental polycyclic aromatic hydrocarbons (ePAHs) as endocrine disruptors. Environ Pollut 213: 809-824.

9. Alia N, Sardar K, Said M, Salma K, Sadia A, et al. (2015) Toxicity and bioaccumulation of heavy metals in spinach (Spinacia oleracea) grown in a controlled environment. Int J Environ Res Public Health 12: 7400-7016.

10. Kong IC (2013) Joint effects of heavy metal binary mixtures on seed germination, root and shoot growth, bacterial bioluminescence, and gene mutation. J Environ Sci (China) 25: 889-894.

11. Lee SM, Lee SB, Park CH, Choi J (2006) Expression of heat shock protein and hemoglobin genes in Chironomus tentans (Diptera, chironomidae) larvae exposed to various environmental pollutants: a potential biomarker of freshwater monitoring. Chemosphere 65: 1074-1081.

12. Singh D, Kumar $A$ (2016) Impact of irrigation using water containing $\mathrm{CuO}$ and $\mathrm{ZnO}$ nanoparticles on Spinacia oleracea grown in soil media. Bull Environ Contam Toxicol 97: 548-553.

13. Bagheri R, Bashir H, Ahmad J, Iqbal M, Qureshi MI (2015) Spinach (Spinacia oleracea L.) modulates its proteome differentially in response to salinity, cadmium and their combination stress. Plant Physiol Biochem 97: 235-245.

14. Kosová K, Vítámvás P, Prášil IT, Renaut J (2011) Plant proteome changes under abiotic stress-Contribution of proteomics studies to understanding plant stress response. J Proteomics 74: 1301-1322.

15. Zhang ZL, Zhu JH, Zhang QQ, Cai YB (2009) Molecular characterization of an ethephon-induced Hsp70 involved in high and low-temperature responses in Hevea brasiliensis. Plant Physiol Biochem 47: 954-959.

16. Ritossa F (1996) Discovery of the heat shock response. Cell Stress and Chaperones 1: 97-98

17. Wang W, Vinocur B, Shoseyov O, Altman A (2004) Role of plant heat-shock proteins and molecular chaperones in the abiotic stress response. Trends Plant Sci 9: 244-252.

18. Duan YH, Guo J, Ding K, Wang SJ, Zhang H, et al. (2011) Characterization of a wheat HSP70 gene and its expression in response to stripe rust infection and abiotic stresses. Mol Biol Rep 38: 301-307.

19. Guo M, Zhai YF, Lu JP, Chai L, Chai WG, et al. (2014) Characterization of CaHsp70-1, a pepper heat-shock protein gene in response to heat stress and some regulation exogenous substances in Capsicum annuum L. Int $\mathrm{J}$ Mol Sci15: 19741-19759.

20. Monterobarrientos M, Hermosa R, Cardoza RE, Gutiérrez S, Nicolás C, et al. (2010) Transgenic expression of the Trichoderma harzianum hsp70 gene increases Arabidopsis resistance to heat and other abiotic stresses. J Plant Physiol 167: 659-665.

21. Harada Y, Sato C, Kitajima K (2015) Sulfatide-Hsp70 interaction promotes Hsp70 clustering and stabilizes binding to unfolded protein. Biomolecules 5 : 958-973.

22. Masand S, Yadav SK (2016) Overexpression of MuHSP70 gene from Macrotyloma uniflorum confers multiple abiotic stress tolerance in transgenic Arabidopsis thaliana. Mol Biol Rep 43: 53-64.

23. Sarkar NK, Kundnani P, Grover A (2012) Functional analysis of Hsp70 superfamily proteins of rice (Oryza sativa). Cell Stress and Chaperones 18 : 427-437.
24. Sung DY, Kaplan F, Guy CL (2001a) Plant Hsp70 molecular chaperones: Protein structure, gene family, expression and function. Physiol Plant 113: 443451.

25. Cho EK, Hong CB (2004) Molecular cloning and expression pattern analyses of heat shock protein 70 genes from Nicotiana tabacum. J Plant Biol 47: 149-159.

26. Guy CL, Li QB (1998) The organization and evolution of the spinach stress 70 molecular chaperone gene family. Plant Cell 10: 539-556

27. Li QB, Guy CL (2001) Evidence for non-circadian light/dark-regulated expression of Hsp70s in spinach leaves. Plant Physiol 125: 1633-1642.

28. Li QB, Haskell DW, Guy CL (1999) Coordinate and non-coordinate expression of the stress 70 family and other molecular chaperones at high and low temperature in spinach and tomato. Plant Mol Biol 39: 21-34.

29. Luo Sq, Ahola V, Shu C, Xu Cr, Wang JR (2015) Heat shock protein 70 gene family in the Glanville fritillary butterfly and their response to thermal stress. Gene 556: 132-141.

30. Sung DY, Vierling E, Guy CL (2001b) Comprehensive expression profile analysis of the Arabidopsis Hsp70 gene family. Plant Physiol 126: 789-800.

31. Wang H, Goffreda M, Leustek T (1993) Characteristics of an Hsp70 homolog localized in higher plant chloroplasts that is similar to DnaK, the Hsp70 of prokaryotes. Plant Physiol 102: 843-850.

32. Yan J, Yu L, Xuan J, Lu Y, Lu S, et al. (2016) De novo transcriptome sequencing and gene expression profiling of spinach (Spinacia oleracea L.) leaves under heat stress. Sci Rep 6: 1-10.

33. Govind G, Harshavardhan VT, Patricia JK, Dhanalakshmi R, Senthil Kumar M et al. (2009) Identification and functional validation of a unique set of drought induced genes preferentially expressed in response to gradual water stress in peanut. Mol Genet Genom 281: 591-605.

34. Tang T, Yu A, Li P, Yang H, Liu G, et al. (2016) Sequence analysis of the Hsp70 family in moss and evaluation of their functions in abiotic stress responses. Sci Rep 6:33650.

35. De Boeck G, De Wachter B, Vlaeminck A, Blust R (2003) Effect of cortiso treatment and/or sublethal copper exposure on copper uptake and heat shock protein levels in common carp, Cyprinus carpio. Environ Toxicol Chem 22 1122-1126.

36. Martini F, Fernandez C, Segundo LS, Tarazona JV, Pablos MV (2010) Assessment of potential immunotoxic effects caused by cypermethrin fluoxetine, and thiabendazole using heat shock protein 70 and interleukin1 beta mRNA expression in the anuran Xenopus laevis. Environ Toxicol Chem 29: $2536-2543$

37. Washburn BS, Moreland JJ, Slaughter AM, Werner I, Hinton DE, et al. (2002) Effects of handling on heat shock protein expression in rainbow trout (Oncorhynchus mykiss). Environ Toxicol Chem 21: 557-560.

38. Abreu IA, Farinha AP, Negrao S, Goncalves N, Fonseca C, et al. (2013) Coping with abiotic stress: proteome changes for crop improvement. J Proteomics 93 145-168.

39. Gu R, Fonseca S, Puskas LG, Hackler L, Zvara A, et al. (2004) Transcript identification and profiling during salt stress and recovery of Populus euphratica. Tree Physiol 24: 265-276.

40. Vasquez-Robinet C, Watkinson JI, Sioson AA, Ramakrishnan N, Heath LS, et al. (2010) Differential expression of heat shock protein genes in preconditioning for photosynthetic acclimation in water-stressed loblolly pine. Plant Physio Biochem 48: 256-264.

41. Wang LJ, Fan L, Loescher W, Duan W, Liu GJ, et al. (2010) Salicylic acid alleviates decreases in photosynthesis under heat stress and accelerates recovery in grapevine leaves. BMC Plant Biol 10: 34

2. Su PH, Li HM (2008) Arabidopsis stromal 70-kD heat shock proteins are essential for plant development and important for thermotolerance of germinating seeds. Plant Physiol 146: 1231-1241.

43. Yang XD, Tan HW, Zhu WM (2016) SpinachDB: a well-characterized genomic database for gene family classification and SNP information of spinach. PLoS One 11: 1-13.

44. Livak KJ, Schmittgen TD (2001) Analysis of relative gene expression data using real-time quantitative PCR and the 2- $\triangle \triangle C T$ method. Methods 25: 402-408.

45. Chen K, Fessehaie A, Arora R (2013) Aquaporin expression during seed 
Citation: Jia W, Liu P (2017) Effects Research of Environmental Hormone BPA and PAEs on the Expression of HSP70-9 Gene in Spinacia oleracea. J Environ Anal Toxicol 7: 438. doi: 10.4172/2161-0525.1000438

Page 6 of 6

osmopriming and post-priming germination in spinach. Biologia Plantarum 57: 193-198.

46. Katschnig D, Bliek T, Rozema J, Schat H (2015) Constitutive high-level SOS1 expression and absence of HKT1;1 expression in the salt-accumulating halophyte Salicornia dolichostachya. Plant Sci 234: 144-154.

47. Chen K, Arora R (2014) Understanding the cellular mechanism of recovery from freeze-thaw injury in spinach: possible role of aquaporins, heat shock proteins, dehydrin and antioxidant system. Physiol Plant 150: 374-387.

48. Basile A, Sorbo S, Cardi M, Lentini M, Castiglia D, et al. (2015) Effects of heavy metals on ultrastructure and Hsp70 induction in Lemna minor L. exposed to water along the Sarno River, Italy. Ecotoxicol Environ Saf 114: 93-101.

49. Jeong B, Jeong ES, Malazarte JM, Sin Y (2016) Physiological and molecular response of Prorocentrum minimum to tannic acid: an experimental study to evaluate the feasibility of using tannic acid in controling the red tide in a eutrophic coastal water. Int J Environ Res Public Health 13: 503-516.

50. Song H, Fan P, Shi W, Zhao R, Li Y (2010) Expression of five AtHsp90 genes in Saccharomyces cerevisiae reveals functional differences of AtHsp90s under abiotic stresses. J Plant Physiol 167: 1172-1178.

51. Liu L, McNeilage RT, Shi LX, Theg SM (2014) ATP requirement for chloroplast protein import is set by the $\mathrm{Km}$ for ATP hydrolysis of stromal Hsp70 in Physcomitrella patens. Plant Cell 26: 1246-1255.

52. Shi LX, Theg SM (2010) A stromal heat shock protein 70 system functions in protein import into chloroplasts in the moss Physcomitrella patens. Plant Cell 22: $205-220$.

53. Hartl FU (1996) Molecular chaperones in cellular protein folding. Nature 381 571-579. 